San Jose State University

SJSU ScholarWorks

Master's Theses

Master's Theses and Graduate Research

1997

\title{
Testing of the Corbin and Cherry Evaluation Tool for Chronic Illness Management
}

Julie Cheitlin Cherry

San Jose State University

Follow this and additional works at: https://scholarworks.sjsu.edu/etd_theses

\section{Recommended Citation}

Cherry, Julie Cheitlin, "Testing of the Corbin and Cherry Evaluation Tool for Chronic Illness Management" (1997). Master's Theses. 1560.

DOI: https://doi.org/10.31979/etd.av54-uwnx

https://scholarworks.sjsu.edu/etd_theses/1560

This Thesis is brought to you for free and open access by the Master's Theses and Graduate Research at SJSU ScholarWorks. It has been accepted for inclusion in Master's Theses by an authorized administrator of SJSU ScholarWorks. For more information, please contact scholarworks@sjsu.edu. 


\section{INFORMATION TO USERS}

This manuscript has been reproduced from the microfilm master. UMI films the text directly from the original or copy submitted. Thus, some thesis and dissertation copies are in typewriter face, while others may be from any type of computer printer.

The quality of this reproduction is dependent upon the quality of the copy submitted. Broken or indistinct print, colored or poor quality illustrations and photographs, print bleedthrough, substandard margins, and improper alignment can adversely affect reproduction.

In the unlikely event that the author did not send UMI a complete manuscript and there are missing pages, these will be noted. Also, if unauthorized copyright material had to be removed, a note will indicate the deletion.

Oversize materials (e.g., maps, drawings, charts) are reproduced by sectioning the original, beginning at the upper left-hand comer and continuing from left to right in equal sections with small overlaps. Each original is also photographed in one exposure and is included in reduced form at the back of the book.

Photographs included in the original manuscript have been reproduced xerographically in this copy. Higher quality $6 " \times 9$ " black and white photographic prints are available for any photographs or illustrations appearing in this copy for an additional charge. Contact UMI directly to order.

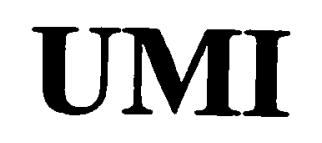

A Bell \& Howell Information Company 
TESTING OF THE CORBIN AND CHERRY EVALUATION TOCL FOR CHRONIC ILLNESS MANAGEMENT

\author{
A Thesis \\ Presented to \\ The Faculty of the school of Nursing \\ San Jose State University
}

In Partial Fulfillment

of the Requirements for the Degree

Master of Science

By

Julie Cheitlin Cherry

December, 1997 
UMI Number: 1388178

Copyright 1997 by Cherry, Julie Cheitlin

All rights reserved.

UMI Microform 1388178

Copyright 1998, by UMI Company. All rights reserved.

This microform edition is protected against unauthorized copying under Title 17, United States Code.

\section{UMI}

300 North Zeeb Road

Ann Arbor, MI 48103 
(C) 1997

Julie Cheitlin Cherry ALL RIGHTS RESERVED 
APPROVED FOR THE SCHOOL OF NURSING

Gelect In. Coebew

Fuliet M. Corbin, R.N., D.N.SC.

$\frac{\text { Aaleew dacker }}{\text { coleen sayior, RgN., Ph.D. }}$ $\frac{\text { Qndrew C.dnes S }}{\text { Andrew C. Irish, R.N., M.N. }}$

APPROVED FOR THE UNIVERSITY

Wielian Futer 


\begin{abstract}
TESTING OF THE CORBIN AND CHERRY EVALUATION TOOL FOR CHRONIC ILLNESS MANAGEMENT
\end{abstract}

by Julie Cheitlin Cherry

The purpose of this research study was to determine if the Symptom Management section of the Corbin and Cherry Evaluation Tool for Chronic Illness Management is a workable, usable tool for measuring outcomes of nursing interventions. Content validity was judged by a panel of five expert nurses. The tool was found to be complete, understandable and easy to use. A retrospective chart review was performed to test the tool for sensitivity and reliability. Statistical analysis using a Wilcoxon signed ranks test showed that the tool is sufficiently sensitive to record shifts in the severity of symptoms before and after nursing interventions. A direct causal relationship between nursing interventions and patient outcomes has yet to be established. These findings have implications for advancing nursing knowledge and conducting outcomes research. 


\section{ACKNOWLEDGMENTS}

To my husband, Russ, thank you for your love and support through this experience.

To my children, Jennifer and Joshua, thank you for your sacrifices (having to eat Dad's cooking), and for making me the proudest Mom alive.

To my parents, Mel and Hella, thank you for supporting my education and believing in me.

And of course--To Julie Corbin, my inspiration, my mentor, and my friend.

Thank you to all of my patients, my friends, my colleagues, and my family, without you, this thesis would not have been possible. 
TABLE OF CONTENTS

Page

LIST OF TABLES . . . . . . . . . . . . . . . . . . . ix

Chapter

1. INTRODUCTION

Background of the Problem . . . . . . . . . 1

Purpose of the Research . . . . . . . . . . 2

Research Questions . . . . . . . . . . 2

Definition of Terms . . . . . . . . . . . 3

Assumptions . . . . . . . . . . . . . . . . 4

2. CONCEPTUAL FRAMEWORK AND LITERATURE REVIEW

The Conceptual Framework . . . . . . . . 5

Literature Review . . . . . . . . . . . 8

3. METHODOLOGY

Development of the Corbin and Cherry Evaluation

Tool for Chronic Illness Management . . . 19

Research Design... . . . . . . . . . 21

Data Collectors . . . . . . . . . . . 21

Subjects . . . . . . . . . . . . . . . . 22

Setting . . . . . . . . . . . . . . 24

Human Subjects Approval . . . . . . . . . 25

Research Procedures . . . . . . . . . 25

Data Collection . . . . . . . . . . 25

Handling of the Data. . . . . . . . . 28 
Analysis Procedures . . . . . . . . . 28

Summary . . . . . . . . . . . . . . . 30

4. ANALYSIS AND INTERPRETATION OF FINDINGS

Demographic Data From Chart Review . . . . . 32

Demographic Description of the Sample. . . 32

Identified Symptom Complaint . . . . . . . 34

Health Provider Action . . . . . . . . . 34

Content Validity . . . . . . . . . . . 37

Clarity and organization . . . . . . . . . 39

Sensitivity of the Symptom Severity

Rating Form . . . . . . . . . . . . 42

Shifts in the Severity Ratings . . . . . . 42

Predictive Analysis of the Health Provider

Action. . . . . . . . . . . . . 42

Interrater Reliability . . . . . . . . . . 44

Summary . . . . . . . . . . . . 50

5. DISCUSSION

Summary of the study . . . . . . . . . . 51

Implications of the study . . . . . . . . . 53

Limitations of the study . . . . . . . . . 58

Significance of the study . . . . . . . . 60

Summary .. . . . . . . . . . . . . 62

REFERENCES . . . . . . . . . . . . . . . 63 
A. Symptom Management Rating Form . . . . . . . . 67

B. List of Trajectory Phases . . . . . . . . 69

C. Visualization of Context . . . . . . . . . 71

D. Memo to Case Managers Requesting

Possible Subjects . . . . . . . . . . 73

E. Approval From Columbia Homecare and Hospice. . . . . . . . . . . . . 75

F. Permission Letter from Chai Health

Nurse Managed Center . . . . . . . . 77

G. Approval Letter from San Jose State

University Graduate Studies and Research . . 79

H. Demographic Data Sheet.. . . . . . . . . 81

I. Code Book for Statistical Analysis. . . . . . . 83

J. Original Symptom Severity Rating Form . . . . 85

K. List of Questions for Content Experts to Address . . . . . . . . . . . . . 87 


\section{LIST OF TABLES}

Table

Page

1. Demographic Characteristics by Setting. . . . . 33

2. The Total Times Each Symptom Complaint

Was Identified . . . . . . . . . . . . . 35

3. The Total Times Each Health Provider

Action Was Implemented . . . . . . . . . 36

4. Relationship Between Health Provider Action and

the Rating of the Severity of the symptom

Before Intervention . . . . . . . . . . 43

5. Ratings Before and After Health Provider

Action by Chart and Data Collector. . . . . 47

6. Summed Ratings of Symptom Severity by Chart

and Data Collector. . . . . . . . . . . . 49 


\section{Chapter 1 \\ INTRODUCTION}

\section{Background of the Problem}

The health care delivery system in the United States is rapidly changing. The costs of health care are soaring. Patients are frequently treated in outpatient settings and hospital stays are brief. In an attempt to contain health care costs, nurses are being replaced by less expensive health care providers. The future for the profession of nursing is uncertain. If the effectiveness of nursing interventions is not recognized, the trend towards downsizing will continue. Therefore, the need for documentation of the effectiveness of nursing interventions is vital to the survival of the nursing profession.

The nursing profession needs research that shows that nursing interventions make a difference in patient outcomes. There are only a few tools available for the measurement of nursing outcomes and they tend to be specific to one problem. Chronic conditions are a major health care problem in the United states today. The treatment of chronic conditions is complex and tends to be very expensive. Nursing interventions are especially important because of the complexity of the care and the need for the patient and/or the caregiver to be taught to 
manage the chronic condition. Nurses need measurement tools that show that nursing interventions have a positive impact on the person's ability to manage his or her chronic condition.

\section{Puxpose of the Research}

The purpose of this research was to determine if the Corbin and Cherry Evaluation Tool for Chronic Illness Management is a workable, usable tool for measuring nursing outcomes in patients with chronic conditions. The Corbin and Strauss Trajectory Framework for Chronic IIlness (1991) served as a theoretical guide for the development of the tool. This framework is a nursing model that clearly guides practice and helps delineate independent nursing functions. This research project examines the section of the tool that measures the severity of symptoms associated with a chronic condition (see Appendix A for a copy of the Symptom Management Rating Form). The tool was designed to measure change or intensity of symptoms before and after nursing interventions.

\section{Research Questions}

The research questions for this study were:

1. Is the Symptom Severity Rating Form complete enough to collect the intended data (symptom complaint, severity rating of symptom, and nursing interventions)? 
2. Is the Symptom Severity Rating Form sufficiently clear and organized to facilitate data collection?

3. Is the Symptom Severity Rating Form sensitive enough to show a shift in the degree of symptom severity before and after nursing interventions?

4. Is data collected by different data collectors reliable using the Symptom Severity Rating Form?

\section{Definition of Terms}

For the purpose of this study, the following definitions apply:

1. Management is an attempt, over the course of a chronic illness, to control or adjust to the symptoms associated with the chronic illness and limit related disabilities (Strauss \& Corbin, 1988).

2. Symptom is a physical or psychological manifestation of an illness (Como, 1990).

3. Nursing Intervention is a purposeful, goal directed action taken by a nurse or nursing student on behalf of a patient (Potter \& Perry, 1989). Nursing interventions in this study are referred to as health provider actions.

4. Chronic Illness is a medical condition that persists over a long period of time, is not self-limiting, has associated symptoms, and can result in disability (Como, 1990; Corbin, 1993; Strauss \& Corbin, 1988). 


\section{Assumptions}

This study assumes that nursing outcomes can be measured. Although the effects of nursing interventions are not independent of other disciplines, it is assumed that nursing interventions play an integral role in positive patient outcomes.

It is also assumed that the data collectors were conscientious in the chart reviews. The researcher assumes the data collectors reviewed the charts thoroughly and gave accurate responses to the sections of the forms. 
Chapter 2

CONCEPTUAL FRAMEWORK AND LITERATURE REVIEW

The Conceptual Framework

Corbin and Strauss developed a nursing model for chronic illness known as the Corbin and Strauss Chronic Illness Trajectory Framework (Corbin \& Strauss, 1991). The model proposes that a chronic illness has a trajectory or course that can be shaped and managed as the status of the illness varies and changes over time. The major premises include: (a) a chronic illness follows a course; (b) an interrelationship exists between the illness course, biography, and everyday life activities; (c) the home is the center of care; (d) management of the course occurs by means of an interactive negotiative process between the patient, family, and care providers; and (e) the course of a chronic illness can be shaped with proper management.

Management of a chronic illness involves identification of the specific trajectory phase, at a given time (see Appendix B for list of trajectory phases). Additionally, the multiple factors affecting the context of illness management are assessed (see Appendix $C$ for visualization of context). These factors have reciprocal impact on each other and therefore, on the illness management. Trajectory projection is the vision of what an 
illness course will be. Trajectory scheme is the plan of how to manage the illness. All key players in a patient's illness have their own trajectory projection and scheme. When the trajectory projections and schemes of all those involved are in alignment, successful management occurs. According to the Corbin and Strauss Chronic Iliness Trajectory Framework, nursing interventions are actions taken by a nurse that help a person manage a chronic illness. The goals of nursing interventions include health promotion, symptom management, and preventing or managing complications, disabilities and/or related psychosocial problems.

The nursing process involves five steps when using the trajectory framework (woog, 1992). These five steps involve an interactive negotiative process. The first step is information gathering, which includes assessing the patient's illness status, biographical history, and everyday Iife activities and the interaction between these. The second step is mutual goal setting. The third step is identifying factors that may facilitate or hinder reaching the goal. The fourth step is initiating interventions. The fifth step is evaluating the effectiveness of the interventions. The trajectory projection and scheme result from this five step process. The patient, family members, physicians, nurses, and other health care providers all 
have their own management context, trajectory projection, and trajectory scheme. It is when these all align, that successful illness management can occur.

The home environment is the primary setting of care in the Corbin and Strauss Chronic Illness Trajectory Framework. The focus of care in chronicity is not on cure; it stresses learning to live with, manage, and adjust to the illness. People who are chronically ill are primarily responsible for shaping their trajectory because they must live with the illness on a daily basis. The goal of nursing care is to facilitate a patient shaping his or her illness course. The Corbin and strauss Chronic Illness Trajectory Framework stresses the importance of the patient and family as active participants in the nursing process.

It is hard to know if nursing interventions are effective without a thorough outcome evaluation. This model addresses and emphasizes the importance of outcome evaluation in the nursing process. Historically, the Corbin and Strauss Chronic Illness Trajectory Framework was built using Grounded Theory (Glaser \& Strauss, 1967; Strauss \& Corbin, 1990). According to Flaskerud and Halloran (1980), "Nursing theory...must explain and predict how nursing actions affect or interrelate...to produce a desired patient outcomen (p. 418). The Corbin and strauss Chronic Illness Trajectory Framework is based on the 
assumption that the combined effort of the multidisciplinary team including the nurse's interventions leads to desired patient outcomes.

The Corbin and Strauss Chronic Illness Trajectory Framework specifically facilitates prediction and prescription for patients. A strong component of the Corbin and Strauss Chronic Illness Trajectory Framework is its attention to the importance of outcome evaluation after nursing interventions. With the current health care reform in the United States, nurses must define their roles and prove their cost effectiveness in independent nursing functions. Nursing the chronically ill, in home and community settings, is now a primary focus in health care delivery. The Corbin and Strauss Chronic Illness Trajectory Framework gives the blueprint needed for fulfilling this nursing role.

\section{Ilterature Review}

In order for the profession of nursing to remain a viable part of our changing health care delivery system, the extent and value of nursing interventions must be recognized (Lang \& Marek, 1992; Snyder, Egan, \& Nojima, 1996). It is imperative that the relationship between nursing interventions and patient outcomes be documented through research. Previous studies have shown that mortality rates are lower in hospitals with higher ratios 
of registered nurses to other health care providers (Aiken, Smith, \& Lake, 1994; Hartz et al., 1989; Weisman, 1992). For example, Aiken, Smith, and Lake (1994) found a five percent lower mortality rate in hospitals identified as having higher ratios of registered nurses to other nursing personnel and good nursing care. Even with these study results, national trends are moving towards replacing registered nurses with less qualified and less expensive unlicensed assistive personnel (DeMoro, 1997).

There has been a shift of control in health care to the payer sources. This shift has led to a different makeup of patients, both in hospitals and communities. Patients are more acutely ill in hospitals and discharged from hospitals before being fully recovered. Consequently, home care is an industry that has significantly grown in response to patients' needs. Home care nurses play a major role in the delivery of health care to these patients. Nursing interventions in home care are regulated by payer sources; therefore, care provided and reimbursed is necessarily delegated by a physician. However, many nursing interventions are independent of physicians' orders. Studies have shown the positive impact the nurse has on the success of patients experiencing early discharge (Inouye et al., 1993; Kennedy, Neidlinger, \& Scroggins, 1987). 
Inouye et al. (1993) authored a large study known as the Yale Geriatric Care Program. This research study tested the effectiveness of a nurse-centered intervention on the functional decline of an elderly hospitalized population. The patients in the intervention group were managed by a team of specially trained nurses. The results supported a $36 \%$ reduction in functional decline in the intervention group compared to the control group.

Kennedy, Neidlinger, and Scroggins (1987) studied the effectiveness of a comprehensive discharge planning protocol (CDPP) on a geriatric population. The protocol was carried out by a gerontological clinical nurse specialist. The authors note that the readmission rate for the elderly hospitalized client was very high (22\%). All of these readmissions were within 60 days of discharge and over $5 \%$ of them were within 5 days of discharge. The authors hypothesized that elderly patients receiving a CDPP by a nurse would experience more positive outcomes after discharge. It is important to note that the CDPP was based solely on independent nursing interventions. The CDPP resulted in clear identification of the patient's post hospitalization needs. The outcome criteria used for this study included: (a) length of hospital stay, (b) readmission within 8 weeks after discharge, and (c) placement after discharge. The researchers found there was 
no difference in placement after discharge between the control group and the study group. However, there was a statistically significant difference $(\mathrm{Q}=0.03)$ in the length of stay for those patients who received the CDPP. The researchers also found the average time before readmission was lengthened by 11 days. These results support the value of nursing interventions for hospitalized elderly patients planning for discharge.

Besides the care ordered by physicians, nurses carry out independent nursing functions as well. Snyder (1985) wrote a textbook which identifies some of these nursing interventions. The author categorizes the independent nursing interventions into three major sections: (a) movement and proprioception interventions, (b) cognitive interventions, and (c) sensory interventions. Snyder discusses each independent nursing intervention and then suggests research that would be valuable to measure the effectiveness of the intervention. For example, the author presents guided imagery as an independent nursing intervention. She includes information specific to the technique of guided imagery and then she presents research that has been done to measure the effectiveness of guided imagery. She concludes with suggestions for future nursing research on the effectiveness of this independent nursing intervention. The nursing profession needs research that 
specifically measures the effectiveness of these types of independent nursing interventions.

Snyder (1985) discusses the reluctance among nurses to perform nursing interventions independent of physicians' orders. She suggests that nurses are not comfortable with the responsibility of making nursing diagnoses, performing appropriate interventions, and then assuming responsibility for their actions. She also suggests that the emphasis for nursing students is on the skills or tasks rather than the autonomous functions a nurse performs. Snyder attempts to identify those functions that are independent nursing interventions and calls for nurses to accept the challenge of autonomous zursing practice.

In a later publication, Snyder, Egan, and Nojima (1996) emphasize the importance of identifying and defining autonomous nursing interventions. The authors stated, "Unless nurses can clearly delineate interventions and outcomes, they will not be recognized for the care delivered nor reimbursed for the care provided whether these interventions have been autonomous or collaborative" (p. 140). The authors suggest that a universal definition of nursing interventions would lead to enhanced collaboration among nurses internationally, a stronger scientific foundation for nursing practice, and ultimately, reimbursement for nursing services. They suggest that when 
nurses work collaboratively with other health care providers, they must be able to delineate what specific nursing functions impact patient outcomes. Without this clarification, nurses are not proven to be cost beneficial in our health care delivery system. Therefore, more research is crucial to measure the effectiveness of independent nursing interventions on patient outcomes.

According to Lang and Marek (1992), outcome studies in nursing began with Florence Nightingale during the Crimean War in 1858. Nightingale used morbidity and mortality rates to emphasize the low standard of care soldiers received during the war. Although morbidity and mortality rates have been used as outcome measures, they fail to identify specific nursing interventions that affect patient outcomes. According to Brooten and Naylor (1995), morbidity is significantly influenced by the medical care received; therefore, it is a good indicator for measuring quality of care. Using morbidity as a measurement of nursing outcomes does not account for the fact that complications, such as infections, are influenced by other health care providers, not just nurses.

Lang and Marek (1992) present an overview of outcome categories that they believe can be used to measure the effectiveness of nursing interventions. The categories they suggest include physiologic, psychological, and 
functional status; behavior; knowledge; symptom control; quality of life; home functions; family strain; goal attainment; utilization of service; safety; resolution of nursing problems; patient satisfaction; and caring. Brooten and Naylor (1995) question whether these outcomes are specific enough to measure the effects of nursing interventions alone. The difficulty of identifying appropriate nursing outcomes that measure the effects of nursing interventions continues to be discussed (Brooten \& Naylor, 1995; Griffiths, 1995; Mark, 1995).

The question remains, how does one measure nursing outcomes? Donabedian (1976) presents a framework for outcome measurement that identifies the structure, process, and outcome as integral components for outcome measurement. In this classic work, which was first presented in 1966 , Donabedian raises the question of whether measuring the structure, process, and outcome can show a casual relationship between the three components.

Waltz and Strickland (1988) compiled a book of measurement tools used specifically to measure nursing outcomes. The measurement tools are divided into categories based on what each tool intends to measure. The categories include: (a) illness oriented measures, (b) wellness measures, (c) outcome measures in community based care, (d) quality of care measures, and (e) measures for 
future directions.

In the same year, Frank-Stromberg (1988) wrote an extremely comprehensive text on instruments appropriate for nursing research. In this text, the measurement tools are categorized as instruments used to measure health and function and instruments used to measure clinical problems. The author emphasizes the need and importance of nurses to develop instruments that can be used for clinical nursing research. She presents several existing barriers to the development of measurement tools in nursing. For example, she suggests that nurses tend to develop their own tools for research projects, they do not thoroughly test the tools for validity and reliability, and then they do not share the tools with other nurses for future nursing research. The author also suggests that there is a lack of tools for measuring the large variety of variables in nursing which has led to a narrow focus in nursing research. Frank-Stromberg suggests that nursing research tends to measure the same variables repeatedly because of this lack of instruments. Lastly, the author emphasizes the importance of the conceptual basis of a tool, the validity and reliability of a tool, and the pretesting or piloting of a tool when nurses are developing instruments to measure nursing outcomes. 
Cherkin (1991) discusses the challenges that nurses face when doing outcomes research. The author notes that the data needed to measure both the process and outcome of interventions is frequently not found in the nurse's notes. Therefore, the data must be located and then collected by the nurse researcher, which is very time consuming, or a new tool must be developed to collect the data. The author also suggests that nurses are challenged to not only support the positive effect nursing interventions have on patients, but also to show that nursing interventions are cost effective. Lastly, Cherkin (1991) points out that most multidisciplinary outcome research does not include nursing interventions as a measurable factor. He emphasizes the importance of nurses becoming involved with this multidisciplinary research, because it can support nursing interventions as useful to patient outcomes.

Nurses have been working diligently to compile information on how to best perform nursing outcomes research. In addition to the books written on nursing measurement tools and methods for nursing outcomes research, nurses have also gathered at national conferences to share information. In 1991, the National Center for Nursing Research held a conference entitled, "Patient Outcomes Research: Examining the Effectiveness of Nursing Practice." The three major accomplishments of the 
conference were: (a) the existing body of knowledge in nursing outcomes research was identified, (b) method and measurement tools were discussed and evaluated for their usefulness, and (c) recommendations for future nursing outcomes research were identified (National Institutes of Health, 1992). The outcome of this conference was a renewed interest in nurses developing methodological tools and resources to conduct effectiveness research.

Currently there is much work being done in the area of nursing outcomes research. Saylor (1997) has developed a classification scheme and identified categories for evaluating outcomes of community health care programs. This classification scheme is useful when researchers are deciding what criteria to use to measure outcomes. By using this classification scheme, one can identify the health outcomes which may be affected by the interventions. The author stresses the importance of linking the outcome criteria to the intervention.

The Corbin and Cherry Evaluation Tool for Chronic Illness Management was developed out of a need to test the assumption that nursing interventions make a difference in patient outcomes. The Corbin and Strauss Chronic Illness Trajectory Framework was the theoretical basis underlying the development of the Corbin and Cherry Evaluation Tool for Chronic Illness Management. With this strong 
theoretical base, the Corbin and Cherry Evaluation Tool for

Chronic Illness Management is an important contribution to nursing outcomes research. 
Chapter 3

METHODOLOGY

Development of the Corbin and Cherry Evaluation Tool for Chronic Illness Management

The Corbin and Cherry Evaluation Tool for Chronic Illness Management was developed using content analysis. The researchers developed the Corbin and Cherry Evaluation Tool for Chronic Illness Management out of a chart review from a nurse managed center in a senior apartment complex. They looked for the most commonly occurring problems presented by the chronically ill elderly. Then they categorized these themes under major headings, which link them back to the theoretical framework, as these were goals for trajectory management. The five headings include: (a) Health Promotion and Disease Prevention, (b) Problems With Symptom Management, (c) Preventing Crisis or Maintaining Stability, (d) Promoting Management of Physical and Mental Disabilities, and (e) Preventing or Minimizing Biographical Problems.

Secondly, the researchers identified the most commonly occurring nursing interventions and conceptualized them into the following categories: (a) provision of direct care, (b) teaching and demonstration, (c) counseling and advising, (d) advocating for clients, (e) monitoring, 
(f) Case management, and (g) arrangement making. Provision of direct care includes interventions such as administering injections, wound care, or changing a Foley catheter. Teaching and demonstration includes providing instruction and/or demonstrating how to perform a task, such as pursedlip breathing or applying a nitroglycerin patch. Counseling and advising involves active listening and providing guidance. Advocating for clients encompasses all those activities that nurses perform to ensure that a patient is provided with the information they need to make decisions about their health care. For example, the nurse may accompany the patient to a doctor's appointment in order to assist the patient in reporting his or her symptoms or to explain to the patient the alternatives that the doctor has proposed. Monitoring is the ongoing process of overseeing the patient's status through assessment and evaluation. This ensures that the nurse is able to intervene early on if a change in the patient's status should arise. Case management includes collaboration with other disciplines in order to coordinate the care plans of the health and social service providers involved in a patient's chronic illness management. Lastly, an example of arrangement making is scheduling transportation for a patient to go to a medical appointment. The next step of tool development for the Corbin and 
Cherry Evaluation Tool for Chronic Illness Management was the preliminary testing of the tool to determine if it was a workable, usable tool. The researcher chose one section of the tool to simplify the testing process and facilitate identification of specific problems with the tool. For this research study, the second section, Problems with Symptom Management was tested. This section was chosen because the researcher believed that complaints of symptoms were frequently the focus of home visits and usually well documented in the nursing progress notes. For this thesis, the symptom management section of the tool is referred to as the Symptom Severity Rating Form.

\section{Research Design}

\section{Data Collectors}

Four registered nurses were hired to perform a retrospective chart review. Two of the nurses were employed at Columbia Homerare and Hospice. One of these nurses was a master's candidate and the other had an associate degree in nursing. The other two registered nurses were affiliated with Chai Health Nurse Managed Center. Both of these nurses were baccalaureate prepared and one was studying in a master's program for nursing. These trained data collectors were each paid $\$ 100.00$ at the completion of the data collection.

The four data collectors were trained for this study 
by the researcher at individual training sessions. The researcher used a written outline for giving the instructions on how to complete the forms and used the same patient's record at all four training sessions to ensure consistency in the instruction given. After a brief overview of the purpose of this study, specific directions were given by the researcher describing how to complete the Demographic Data Sheet and the Symptom Severity Rating Form. The researcher and the data collector jointly read a patient's record and then discussed the scenario. Then the researcher had the data collector complete the Demographic Data Sheet and the Symptom Severity Rating Form for that patient scenario.

The data collectors were told they would be given the names and identification numbers of 20 subjects from their agency and 2 subjects from another agency. They were instructed to complete only one problem on each symptom Severity Rating Form. They were not given a limit on the number of forms they could complete for each patient; however, they were told to complete a total of at least 20 forms for the study.

Subjects

A total of 80 cases were selected through a purposive, nonrandom sampling procedure. Cases were chosen based on the following criteria: (a) 65 years of age or older, 
(b) diagnosis of at least one chronic illness, and (c) complaint or demonstration of difficulty managing a symptom related to the chronic illness.

The researcher sent out a memo to the Case Managers at Columbia Homecare and Hospice and the Chai Health Nurse Managed Center requesting names and identification numbers of patients that fit the selection criteria (see Appendix D for a copy of the memo). Fifty-five names were obtained from Columbia Homecare and Hospice and fifty names were obtained from Chai Health Nurse Managed Center. Each name was written on a separate piece of paper. The pieces of paper were then folded in half and put in one of two baskets, depending on which agency they came from. The researcher then pulled 40 names out of the Columbia Homecare and Hospice basket and 40 names from the Chai Health Nurse Managed Center basket. Then the 40 names were randomly divided into two more piles, one for each data collector from each prospective agency. The researcher purposefully chose two additional patients from each agency to be used for interrater reliability review. A list was then compiled for each data collector with the patients' names and identification numbers. Included on this list for each data collector were the four patients chosen for interrater reliability. None of the data collectors were aware that they would be reviewing these same four charts. 


\section{Setting}

The cases were collected from two different

facilities, Columbia Homecare and Hospice, and the Chai Health Nurse Managed Center. Columbia Homecare and Hospice is a home care agency that provides services to a wide variety of patients in both rural and urban communities. All nursing services are provided under the direction of a physician. The patients chosen for this study were recruited from the Medicare division of this home care agency, helping to ensure that these patients would meet the selection criteria.

The Chai Health Nurse Managed Center is a community based clinic in a senior apartment complex. Nursing services are directed, provided, and supervised solely by nurses. The majority of the care is provided by student nurses from San Jose State University under the direction of a faculty advisor. The clinic is managed by a paid, part-time registered nurse. The nurses work collaboratively with social workers and the apartment complex manager. Most services provided are independent of physician's orders. Some of these independent nursing interventions include holding blood pressure clinics, health and wellness classes, doing crises intervention, physical assessment, and making referrals when appropriate. The nurses are also available to perform specific medical 
interventions under a physician's order when appropriate. For example, monthly Vitamin B12 injections can be administered with a physician's written order.

\section{Human Subjects Approval}

The researcher presented the research proposal to the Columbia Homecare and Hospice Research Committee, and approval was granted to access patient records for the study (see Appendix E for copy of written approval). Written permission was also granted to use health records at Chai Health Nurse Managed Center by the Director (see Appendix F for copy of written permission). With these permission letters, the researcher submitted a research proposal and written request to the Human SubjectsInstitutional Review Board of San Jose State University Graduate Studies and Research. The researcher obtained approval to use human subjects in the study (see Appendix G for copy of written approval).

\section{Research Procedures}

\section{Data collection}

Chart Review. The researcher gave each data collector the appropriate list of patient's medical records to review. Then the data collector pulled those records and reviewed each one individually. First, the demographic data were obtained from the patient record and recorded on the Demographic Data Sheet. Then the nursing notes in the 
record were read visit by visit. After the data collector had studied the record to gain an understanding of the patient scenario, the Symptom Severity Rating Form was completed.

Demographics. The following demographic information was recorded: (a) patient identification number, (b) facility, (c) date of birth, (d) gender, (e) list of chronic illnesses, (f) number of medications listed in the record (including over the counter medications), and ( $g$ ) specific symptom complaint (see Appendix H for a copy of the Demographic Data Sheet).

Completion of the Symptom Severity Rating Form. In the first section of the Symptom Severity Rating Form, Client Problem, the data collector chose one symptom that the patient was having difficulty managing. The degree of difficulty managing the symptom was then rated on a likert scale from one to five. One represented the lowest degree of difficulty with symptom management and five represented the highest degree of difficulty with symptom management. Once the rating was determined the data collector considered all the nursing interventions that had taken place over time to help the patient with symptom management. In the second section of the Symptom Severity Rating Form, Health Provider Action, the data collector circled yes or no if that category of nursing intervention 
had taken place. If yes was circled, the data collector wrote a brief description of the nursing intervention. Lastly, in the third section of the symptom severity Rating Form, Client Response, the data collector again rated on a Likert scale the degree of difficulty the patient had with symptom management after the nursing intervention/s.

After completion of the data collection the researcher spoke individually with each data collector about her experience using the Symptom Severity Rating Form. Identification of the Symptom Severity Rating Form's strengths and weaknesses were discussed. Specifically, the researcher was interested to know if the data collectors found the Symptom Severity Rating Form easy to use or difficult to use.

Upon completion of the data collection by all four data collectors, the Demographic Data Sheets and Symptom Severity Rating Forms were collected by the researcher. The researcher wrote the initials of the data collector who completed that form in the upper left hand corner of each Demographic Data Sheet. Then the researcher compiled the data on each Demographic Data Sheet by writing the total number of chronic illnesses in the right side column of each Demographic Data Sheet. The researcher then wrote a code book for the statistical analysis of the data (see Appendix I for a copy of the code book). The researcher 
formatted all the data into a computer program and mailed the disk to the statistician for analysis.

Handling of Data

Confidentiality was protected by each record being recorded by the patient identification number only. No names were transferred to the Demographic Data Sheet or the Symptom Severity Rating Form. When the data collection was completed, the researcher kept the records in a locked briefcase for transfer to the researcher's home. The data were then stored in the researcher's home in a locked file cabinet. The researcher mailed photo copies of the data and a computer disk to the statistician. The envelope was clearly marked "confidential". The sealed envelope was received by the statistician with no evidence of tampering. Analysis Procedures

Statistical analysis was performed by a hired statistician. The statistical analysis of the symptom Severity Rating Form included a consideration of validity and interrater reliability. Descriptive statistics were also obtained to describe the sample used in the chart review. Lastly, a nonparametric statistical test (the wilcoxon signed ranks test) was utilized to consider the sensitivity of the Symptom Severity Rating Form.

content Validity. Validity is defined by Polit and Hungler (1991) as "the degree to which an instrument 
measures what it is intended to measuren (p. 657). For this study, the researcher focused on content validity, which is the degree to which the specific items in the Symptom Severity Rating Form represent the entire scope of possibilities with regards to the content. For example, if all possible symptoms and nursing interventions were included in the categories listed on the Symptom Severity Rating Form.

Content validity was determined by review of the Symptom Severity Rating Form (in its original form) by a panel of five expert nurses (see Appendix $J$ for a copy of the original form). One of the nurses was an expert in outcome evaluation, three were experts in chronic illness management, and one was an expert in tool development. The experts were given a list of questions to address when evaluating the Symptom Severity Rating Form (see Appendix $K$ for a copy of questions). The revisions deemed necessary after the experts' review were implemented before the data collection was initiated (refer to chapter four for the results of the experts' review).

Interrater Reliability. Reliability is defined by Polit and Hungler (1991) as "the degree of consistency or dependability with which an instrument measures the attribute it is designed to measuren (p. 653). For this study, reliability was measured in terms of interrater 
reliability. This is the assurance that there is consistency in the scoring of the symptom Severity Rating Form among different data collectors.

Interrater reliability was determined by having five percent of the total cases (four cases) reviewed by all four data collectors. The data collectors were not aware which cases were being reviewed for interrater reliability. The completed symptom Severity Rating Forms from each data collector were compared for internal consistency of ratings and results. A Cronbach's alpha was calculated for the reliability index.

Symptom Severity Rating Form Sensitivity. The sensitivity of the Symptom Severity Rating Form was determined by statistical analysis of the severity ratings. Utilizing the Biomedical Data Processing statistical Software Manual (Dixon, 1993), a Wilcoxon signed ranks test was run. This nonparametric statistical test was used to measure if a change in ranking existed before and after the health provider actions and then considered multiple variables as possible predictors of the change.

\section{Summary}

The Corbin and Cherry Evaluation Tool for Chronic Illness Management was developed by content analysis. Client problems and nursing interventions were conceptually categorized resulting in a five section tool. The symptom 
management section of the tool was chosen for this study to determine the usability of the tool.

Four registered nurses were trained as data collectors. They all received the same training and instructions for completing the data collection forms. A total of 80 cases were selected through a purposive nonrandom sampling procedure. Half were from Columbia Homecare and Hospice and the other half were from Chai Health Nurse Managed Center. The researcher received human subjects approval from both community settings as well as San Jose State University before beginning the study.

Each data collector reviewed the assigned client records and then filled out a Demographic Data Sheet and a Symptom Severity Rating Form for each symptom identified. After the data collection was completed, the researcher spoke individually to the data collectors to receive feedback on their experience using the forms.

Content validity was determined by review of the Symptom Severity Rating Form by five expert nurses. The sensitivity of the Symptom Severity Rating Form was determined by a chart review. Interrater reliability was measured by review of five percent of the total records by all four data collectors. The results of the study were statistically analyzed utilizing the Biomedical Data Processing Statistical Software Manual (Dixon, 1993). 
Chapter 4

ANALYSIS AND INTERPRETATION OF FINDINGS

The purpose of this study was to determine if the symptom management section of the Corbin and Cherry Evaluation Tool for Chronic Illness Management was a workable, usable tool. This chapter presents a demographic description of the sample, the results of the content analysis, data collector's experience, and statistical analysis of the data collected through a chart review. Following the demographic description, the analysis of the findings is presented as it relates to the research questions.

\section{Demographic Data From Chart Review}

\section{Demographic Description of the Sample}

A final sample consisting of 77 symptom Severity Rating Forms was obtained from the chart review. Table 1 presents an overview of the demographic data describing these clients. Thirty-five of the Symptom Severity Rating Forms (45.45\%) were collected from Columbia Homecare and Hospice and 42 of the Symptom Severity Rating Forms (54.55\%) were obtained from Chai Health Nurse Managed Center. Twenty-seven Symptom Severity Rating Forms (35.06\%) were from charts of male clients, 48 Symptom Severity Rating Forms (62.348) were from charts of female 
Table 1

Demographic Characteristics by setting

\begin{tabular}{llll}
\hline $\begin{array}{l}\text { Demographic } \\
\text { Characteristics }\end{array}$ & Columbia & Chai Health & Total \\
\hline Number of Clients & 35 & & \\
Gender & 15 male & 12 male & 27 male \\
& 20 female & 28 female & 48 female \\
Mean Age (years) & 75.70 & 88.70 & 81.54 \\
Mean Chronic Illnesses & 2 & 3 & 2.51 \\
Mean Medications & 6 & 9 & 7.88 \\
\end{tabular}


clients, and 2 (2.60\%) were not identified for gender. For the total population, the mean age of the clients was 81.54 years. The most common number of chronic illnesses was two (44.168). The most common number of medications a client was taking was between 8 and 10 (41.56\%).

This sample reflects a population of elderly clients, living in the community, who have multiple chronic illnesses and fairly complex medical regimes as evidenced by the large number of medications. Identified Symptom Complaint

As outlined in Table 2, seven Symptom Severity Rating Forms (9.09\%) identified the symptom of energy deficit. Sixteen forms $(20.77 \%)$ identified the symptom of pain. Forty-six forms (59.74\%) identified physiological symptoms. One form ( $1.30 \%$ ) identified symptoms related to appetite, and seven forms ( $9.09 \%)$ identified medication symptoms. Health Provider Action

As outlined in Table 3, provision of direct care was identified as a health provider action 43 times (55.84\%). Teaching and demonstration was provided 64 times (83.12\%). Counseling and advising was provided 55 times (71.43\%). Advocating was provided 39 times (50.65\%). Monitoring was provided 54 times $(70.138)$. Case management was provided 54 times (70.138). Arrangement making was provided 24 times $(31.17 \%)$. 
Table 2

The Total Times Each Symptom Complaint was Identified

\begin{tabular}{lcc}
\hline Symptom Complaint & $\underline{\mathbf{n}}$ & Percent of Total Sample \\
\hline Energy Deficit & 7 & 9.09 \\
Pain & 16 & 20.77 \\
Physiological & 46 & 59.74 \\
Appetite & 1 & 1.30 \\
Medications & 7 & 9.09 \\
\hline
\end{tabular}

Note: The total sample size was 77 . 
Table 3

The Total Times Each Health Provider Action Was Implemented

\begin{tabular}{lcc}
\hline Health Provider & $\begin{array}{l}\text { Number of Times } \\
\text { Action Is Provided }\end{array}$ & $\begin{array}{c}\text { Percent of } \\
\text { Time Provided }\end{array}$ \\
\hline Provision of Direct Care & 43 & 55.84 \\
Teaching and Demonstration & 64 & 83.12 \\
Counseling and Advising & 55 & 71.43 \\
Advocating for Client & 39 & 50.65 \\
Monitoring & 54 & 70.13 \\
Case Management & 54 & 70.13 \\
Arrangement Making & 24 & 31.17 \\
\hline
\end{tabular}

Note: The total sample size was 77 . 


\section{Content Validity}

The first research question was: Is the form complete enough to collect the intended data? The content experts who reviewed the original symptom Management section of the Corbin and Cherry Evaluation Tool for Chronic Illness Management were insightful and gave thoughtful recommendations for revisions to the Symptom Severity Rating Form. In regards to the terminology used in the Symptom Severity Rating Form, the experts identified a need for clarification of the terms used in the health provider action section. Specifically, they suggested the necessity of differentiating between arrangement making, referral making, and case management. The researcher determined that referral making is a function of case management; therefore, it was subsumed under that heading and was dropped as a category. The researcher clarified that case management was defined as the coordination of care plans between health care providers, whereas arrangement making was defined as actions, such as setting up transportation or making an appointment for a patient.

Several comments were made regarding the Likert scales. The scales caused some confusion for the content experts. The Likert scale for the rating after nursing interventions was different than the scale used before nursing interventions. The symptom severity Rating Form 
was developed to measure the same variable before and after nursing interventions; therefore, the researcher changed the second likert scale to be identical to the first likert scale.

The original Symptom Severity Rating Form had two other Likert scales that were omitted on the revised form. One rated the appropriateness of each health provider action that was performed. As two content experts suggested, nurses would not perform an action that was inappropriate; therefore, rating the appropriateness of the intervention was unnecessary. The other likert scale that was omitted was designed to rate the overall degree of success in control over the symptom. It was decided that this was unnecessary because it was a duplication of the rating after nursing interventions.

Two of the content experts raised concerns regarding the cluttered appearance of the Symptom Severity Rating Form. By eliminating two of the likert scales and the space for totaling the health provider actions, the symptom Severity Rating Form appeared less cluttered and easier to read. Additionally, it was suggested that written directions for filling out the symptom Severity Rating Form be included. The researcher chose to reword the headings, change the title, and emphasize the words "beforen and "after" on the form to help clarify how to fill out the 
form. Written directions were deemed unnecessary after these changes were implemented.

The strengths recognized by the content experts review of the Symptom Severity Rating Form included that the terminology in the identified problem section was very clear and understandable. One expert commented that even with poor vision the scales were easy to read. The experts were in agreement that the form had strong potential to measure what it was intended to measure. They were optimistic that the Symptom Severity Rating Form would be sensitive enough to pick up any shift in the degree of difficulty with symptom management from before to after nursing interventions.

\section{Clarity and Organization}

The second research question was: Is the form formatted in a manner that is both clear and organized, facilitating data collection? The data collectors agreed that the symptom Severity Rating Form was clear and easy to use. Through the process of chart review the data collectors found that the form encompassed all possible categories of symptoms and health provider actions. There were no patient scenarios that they were unable to complete a form on for lack of a category.

The main problem identified with the process of data collection was finding the information in the nurses' notes 
from the Chai Health Nurse Managed Center charts. Most of the charting is done by student nurses. Often, the nursing assessment and interventions were clearly charted, but the follow-up related to the identified problem was missing. The data collectors unanimously agreed that retrieving data from the charting at Columbia Homecare and Hospice was much easier. The charting at Columbia Homecare and Hospice is systems oriented on a standardized form. There are clear sections delineated for charting the nursing assessment, interventions, and follow-up. This format is required by regulatory agencies, such as Medicare, and ensures that outcomes of interventions are clearly documented.

The data collectors found that patients at Columbia Homecare and Hospice were more acutely ill; therefore, the interventions were more purposeful and easily identified. The clients at Chai Health Nurse Managed Center were more chronically ill, and because it is an outpatient clinic setting, the focus of care is more on preventative care with early detection and intervention. These types of interventions are implemented over longer periods of time and not as easy to track in the patient's chart. Also, the student nurses are at Chai Health Nurse Managed Center once a week for only one semester. Then they leave and a new group of students comes to the clinic. Often one problem is resolved and/or another arises between nursing visits, 
perhaps explaining some of the apparent lack of charting on follow-up.

All four data collectors agreed that it was much easier to rate a patient's degree of difficulty with symptom management when the data collector was familiar with the patient scenario. This raises the interesting question of who should fill out the symptom Severity Rating Form. Perhaps it should be a negotiative process between the nurse and the patient.

Three of the four data collectors did not follow the instructions to briefly describe the health provider actions that were implemented. When questioned why, none of the collectors remembered seeing an instruction asking them to describe the health provider actions. The researcher will enlarge the prompt on the Symptom Severity Rating Form and bold the print so it stands out to avoid this oversight in the future.

Another recommendation made by one data collector was to have written definitions of the health provider actions in order to increase the clarity of these categories. One data collector had written her own definitions during the training session and found herself referring back to the definitions frequently during the data collection. The researcher will write clear definitions of the health provider actions, with examples, to accompany future use of 
the Symptom Severity Rating Form.

\section{Sensitivity of the Symptom Severity Rating Form}

\section{Shifts in the Severity Ratings}

The third research question was: Is the form sensitive enough to show a shift in the degree of symptom severity? To determine if there is a difference in the ratings for symptom severity before health provider actions versus after health provider actions, a Wilcoxon signed ranks test was utilized. The severity rating before health provider action was compared to the severity rating after health provider action. The wilcoxon test showed a statistically significant change $(Q<.001)$ from the severity of the symptoms before the health provider actions to the rating after the health provider actions. This test describes changes, and the finding of statistical significance suggests that the interventions did have an effect since there were different scores before and after interventions. This analysis suggests that the symptom Management section of the Corbin and Cherry Evaluation Tool for Chronic Illness Management is sensitive enough to measure a shift in symptom severity from before to after nursing interventions.

\section{Predictive Analysis of the Health Provider Action}

Table 4 illustrates relationships between the health provider actions and the symptom severity rating. 
Table 4

Relationship Between Health Provider Action and the Rating of the Severity of the Symptom Before Intervention

\begin{tabular}{|c|c|c|c|c|c|}
\hline \multirow[t]{2}{*}{$\begin{array}{l}\text { Category of } \\
\text { Health Provider Action }\end{array}$} & \multicolumn{2}{|c|}{$\begin{array}{l}\text { Symptom } \\
\text { Severity } \\
3\end{array}$} & $\begin{array}{l}\text { Symptom } \\
\text { Severity } \\
4\end{array}$ & \multicolumn{2}{|c|}{$\begin{array}{l}\text { Symptom } \\
\text { Severity } \\
5\end{array}$} \\
\hline & $\underline{\mathrm{n}}$ & $(z)$ & $\underline{\underline{n}}(q)$ & $\underline{\underline{ }}$ & $(\xi)$ \\
\hline Provision of Direct Care & 14 & $(338)$ & $12(288)$ & 17 & $\left(40 \frac{8}{6}\right)$ \\
\hline Teaching and Demonstration & 14 & $(22 \%)$ & $29(458)$ & 21 & $(33 \%)$ \\
\hline Counseling and Advising & 4 & $(78)$ & $27(498)$ & 24 & $(44 \%)$ \\
\hline Advocating for Client & 4 & $(108)$ & $16(418)$ & 19 & $(49 \%)$ \\
\hline Monitoring & 4 & $(78)$ & $27(5 \%)$ & 23 & $(43 \%)$ \\
\hline Case Management & 10 & $(19 q)$ & $24(448)$ & 20 & $(37 \%)$ \\
\hline Arrangement Making* & 2 & $(8 \%)$ & $6(258)$ & 16 & $(67 \%)$ \\
\hline
\end{tabular}

Note: * $\underline{D}<.01$. As the severity rating increases, the percent of times a health provider action is implemented increases. 
A Spearman's Correlation Coefficient was used to examine the relationship between ratings of severity and frequency of health provider actions for each of the seven types of provider actions. Arrangement making was the only health provider action that had a statistically significant increase $(p<0.01)$ in frequency of the action taken in relationship to an increase in the severity of the symptom rating by 3,4 , or 5 . There were trends in other health provider actions with higher frequencies of action taken in relation to higher severity ratings, but these were not significant across all three severity ratings. The higher frequency of implementing arrangement making when a high severity rating exists makes sense because when symptoms are severe, the nurse must take action to see that the patient is diagnosed and treated. This is usually done by arranging for the patient to see a physician. Perhaps this nursing intervention has the greatest impact on patient outcomes because it is the nurse's intervention that initiates the chain of events that eventually lead to symptom control.

\section{Interrater Reliability}

The fourth research question was: Is data collected by different data collectors reliable? Four charts were reviewed by each of the four data collectors to determine interrater reliability. A Cronbach's alpha was utilized to 
estimate the internal consistency of the data collected from these four charts. Specifically, a comparison between the data collectors' information regarding the type of symptom identified, the health provider actions implemented, and the severity rating of symptoms before and after the health provider actions were analyzed. Before the specific results are presented, it is important to consider what a measurement of reliability means.

As stated in Polit and Hungler (1991), "Reliability is the proportion of true variability to the total obtained variability" (p.373). Reliability is a measure of variance or differences in a set of scores. For this study, reliability was the measure of the probability that differences in the severity ratings among patients would be picked up by the raters. If no differences in the severity of symptoms existed between the patients, then there was no chance for variation to be picked up. In the absence of variability it is not possible to calculate a high reliability coefficient.

To begin with, the reliability coefficient computed for the symptom that the data collectors identified in each chart was 0.68 . This means that only $68 \%$ of the variance in the scores is explained by the agreement between the data collectors. This number is low because the recorded symptoms in each chart were not varied enough for the form 
to measure differences with any statistical significance.

Table 5 represents the results of the symptom severity ratings from the four charts by the four data collectors. Notice that each chart was rated with a high severity rating before the health provider action and a low rating after the health provider action. As a consequence of these homogeneous scores the reliability coefficients are low. Specifically, the reliability coefficient computed for ratings before the health provider action was 0.00 . The reliability coefficient for ratings after the health provider action was 0.59 .

To summarize the interrater reliability scores, this study did not present a large enough spread in the type of symptoms or the severity of the symptoms between patients to ascertain the interrater reliability with any. statistical significance. It is important to reiterate the desired outcome of using the symptom severity Rating Form. It was hoped that the data collectors would identify the same symptom per client in the chart review and would similarly rate the degree of difficulty with management of that symptom. This did occur in this study; however, with the small sample size and the similarity between patients. the measure of reliability was low.

In order to further analyze the low reliability finding, an analysis of variance was calculated using data 
Table 5

Ratings Before and After Health Provider Action by Chart and Data Collector

\begin{tabular}{lcccc}
\hline & Collector & Collector & Collector & Collector \\
& 1 & 2 & 3 & 4 \\
& Before/After & Before/After Before/After Before/After \\
\hline Chart 1 & $5 / 2$ & $4 / 2$ & $4 / 2$ & $5 / 2$ \\
Chart 2 & $4 / 3$ & $4 / 2$ & $3 / 2$ & $5 / 2$ \\
Chart 3 & $5 / 2$ & $4 / 3$ & $5 / 4$ & $4 / 3$ \\
Chart 4 & $5 / 2$ & $4 / 2$ & $4 / 3$ & $4 / 2$ \\
\hline
\end{tabular}


collectors and charts as the two dependent variables. Table 6 shows the sums of the symptom severity ratings of each of the four data collectors for each of the four charts reviewed. The analysis of variance showed only the data collector variable as a statistically significant factor $(p=0.0082)$. That is, the data collectors account for differences in severity ratings rather than the variable of the patient charts.

There were several differences among the data collectors. Educationally, data collector number 1 and 2 were studying in a master's program in nursing. Data collector number 3 was an associate degree nurse who was pregnant at the time of the data collection and was unable to finish before the baby was born. She then returned during her recovery to complete her data collection. Data collector number 4 was a baccalaureate prepared nurse who had recently begun working at Chai Health Nurse Managed Center. She was the least familiar with the clients and the charting systems from the two facilities. Notice that the ratings from data collector number 3 were the least similar to the other data collectors. On chart numbers 2 , 3 , and 4 her ratings were much different than the other three data collectors, although she identified the same symptoms as the other three data collectors. 
Table 6

Summed Ratings of Symptom Severity by Chart and Data Collector

\begin{tabular}{lcccc}
\hline & Collector & Collector & Collector & Collector \\
& 1 & 2 & 3 & 4 \\
\hline Chart 1 & 5 & 3 & 4 & 4 \\
Chart 2 & 6 & 6 & 2 & 5 \\
Chart 3 & 7 & 6 & 3 & 4 \\
Chart 4 & 7 & 6 & 2 & 4 \\
\hline
\end{tabular}


Another possible limitation due to the data collectors was the fact that they were not sufficiently trained to pick up subtle differences in the chart review. For example, no specific definitions were provided to differentiate the different possible ratings other than the words very low, low, moderate, high, and very high.

\section{Summary}

The Symptom Management Section of the Corbin and Cherry Evaluation Tool for Chronic Illness Management was found to be complete, understandable and easy to use. Statistical analysis supports the fact that a shift exists in the severity of symptoms from before nursing interventions to after nursing interventions, and the Symptom Severity Rating Form is sensitive enough to record this shift. The results for interrater reliability were low; however, they are partially understandable by the lack of subject variability in the study. The difference in the data collectors also partially explains the outcome of this reliability study. 
Chapter 5

DISCUSSION

\section{Summary of the Study}

The development of a data collection tool involves a multi-step process. The first step is to create a tool. The creation of the Corbin and Cherry Evaluation Tool for Chronic Illness Management was grounded in practice. Through the qualitative process of content analysis this tool was developed in hopes of quantifying the effect of nursing interventions and supporting their value to patient outcomes. The Corbin and Strauss Chronic Illness Trajectory Framework served as a conceptual guide to developing this tool.

This research study was the second step in the development of the Corbin and Cherry Evaluation Tool for Chronic Illness Management. The researcher examined the Symptom Severity Rating Form, which is the Symptom Management section of the Corbin and Cherry Evaluation Tool for Chronic Illness Management. Specifically, the study examined if the symptom Severity Rating Form is a useable, workable form for data collection. Revisions to the original form were made after a panel of expert nurses examined the form for content validity. Then by way of a retrospective chart review four trained data collectors 
gathered data using the form. Patient records were chosen for the study through a purposive, nonrandom sampling procedure from two community health agencies. One setting was Columbia Homecare and Hospice, a licensed home care agency. The other setting was Chai Health Nurse Managed Center, a nursing clinic in a senior residential apartment complex.

A total sample of 77 Demographic Data Sheets and Symptom Severity Rating Forms were completed by the chart review. Demographically, the sample studied was comprised of elderly persons living in the community, with multiple chronic illnesses and multiple medications.

Content validity of the Symptom Severity Rating Form was supported by review of the form by five expert nurses. Several revisions to the original form were implemented resulting in a clear, easy to read, understandable format, which was then used for the chart review.

The data collectors found the Symptom Severity Rating Form easy to use and co:mlete enough to collect the data intended. A problem with the clarity of the terms in the health provider actions section and the instructions to briefly describe the health provider actions was discovered through the process of the chart review. Some difficulty was experienced with finding the data in the nurses' notes. One explanation may be that charting at Chai Health Nurse 
Managed Center is done primarily by student nurses who provide intermittent, short term care. These student nurses are in the process of learning and there can be great variance in their charting ability based on their experience and knowledge.

A wilcoxon signed ranks test found a statistically significant difference $(\mathbb{D}<.001)$ between the severity of the symptom rating before the health provider action and the rating after the health provider action. This indicates that the Symptom Severity Rating Form is sensitive enough to record shifts in the severity of symptoms. The one health provider action that was found to be a predictive variable for a high severity rating was arrangement making.

A Cronbach's alpha computed a low reliability coefficient for interrater reliability. The interrater reliability was low because there was little variance in the sample. The data collectors were one possible confounding variable to these results. An examination of the data collectors identified education, experience, and personal factors that could have influenced data recorded.

\section{Implications of the study}

This study suggests that the symptom Severity Rating Form is a workable, usable form. The data from this study show that a change exists in symptom severity after nursing interventions, and the form is sensitive enough to capture 
the change. However, the challenge remains to show a direct link between the change in symptom severity and the nursing interventions. Although the change in symptom severity after nursing interventions suggests cause and effect, this still needs to be substantiated through appropriate research designs.

Examining the effects of nursing interventions is quite a challenge considering the multiple factors that can affect patient outcomes. For example, if a patient is having increased shortness of breath related to congestive heart failure a combination of interventions are set into motion: (a) The physician may change medications, (b) the nurse may teach about the medication's affects and side effects and reinforce the necessity to take the medications as prescribed, (c) the physical therapist may teach activity pacing and get the patient a bedside commode, and (d) the family may change its cooking habits to reduce salt in the patient's diet. It is a combination of all these interventions that leads to a reduction in the patient's symptom of increased shortness of breath.

The next step in tool development for the Corbin and Cherry Evaluation Tool for Chronic Illness Management is demonstrating a relationship between the shift in symptom severity and the nursing interventions. This study indicates that when the symptom severity rating was high, 
the health provider action, arrangement making, was implemented. Therefore, the researcher suggests studying the number of times arrangement making was implemented and attempting to correlate it with a change in the severity of symptoms.

Showing this relationship is a challenge. Most nursing interventions are only a part of the multistep, multidisciplinary process that is involved in symptom management. For example, after the nurse identifies a problem that needs the attention of a physician, he or she makes the arrangements for the patient to be seen. Then the patient must follow through and see the physician; the physician must follow through and provide a treatment; the patient must follow through and carry out the treatment regimen. It is only at this point that the patient may feel the symptom is less severe. It is possible the patient will not recognize any correlation between the nurse's initial intervention and the outcome of better symptom management. In fact, a direct relationship between the nursing intervention and the patient outcome does not exist, and even an indirect relationship might be difficult to capture in a research study. This is only one explanation of the difficulty and complexity of outcome evaluation studies, not only for nursing, but for other health care disciplines as well. 
Many other questions evolved during this research study. For example, on a number of occasions, the researcher revisited the question of what is this tool really measuring. In the beginning of the tool's development, the researcher intended to measure the degree of difficulty the patient was having managing symptoms associated with a chronic illness. Through the research process, the researcher discovered the best way to measure this was to rate the severity of the symptoms. Although the initial intent was to rate the degree of difficulty with symptom management, the data collected actually describes a rating of symptom severity. The researcher assumes that a rating of symptom severity actually measures a patient's level or ability to control or manage a symptom. The researcher plans to change the terminology on the form from Rate the degree of difficulty with symptom management to Rate the degree of symptom severity.

The question of interrater reliability is also one that needs attention in future research. In order to estimate interrater reliability more accurately for the Symptom Severity Rating Form, a larger sample of patients with increased variation of symptom severity is needed. The results of this study also suggest other changes be made on the Symptom Severity Rating Form in future research. Better instruction must be given to data 
collectors. Greater precision in the definitions associated with the categories on the symptom Severity Rating Form would probably facilitate the data collection process. The data collectors need a high level of knowledge about the particular research being conducted and the importance of accurate data collection. Perhaps their level of personal investment in the project needs to be higher than it was for some of the data collectors in this study. This may be achieved through better training and testing of that training.

Another important question that arose out of this study was who should collect the data? Since severity of symptom is a subjective definition, perhaps a negotiative process between the nurse and the patient would lead to greater accuracy of the data collected. As the data collectors had greater familiarity with the patient scenarios, they stated that their level of confidence that they were collecting accurate data increased. Additionally, the data needed was not always in the nurse's notes. These factors provide limitations to a retrospective chart review and suggest a possible increase in accuracy of the data if collected over the period of time the symptom was problematic and the patient was cared for by the nurse. 


\section{Iimitations of the Study}

Perhaps one of the greatest limitations to this study was the data collectors' heavy dependence on the nurse's charting for data. The researcher attempted to address this by using the symptom Management section of the Corbin and Cherry Evaluation Tool for Chronic Illness Management. Complaints of symptoms are frequently the focus of home visits; therefore, they are usually well documented in the nursing progress notes.

At Chai Health Nurse Managed Center the charting is predominately done by student nurses. These nurses typically have weaker charting skills than an experienced nurse. Additionally, at Chai Health Nurse Managed Center there is little prompting built into the charting procedure because the student nurses are supposed to be learning the skill of charting progress notes. At Columbia Homecare and Hospice, the charting is facilitated by using nursing notes that are designed with prompts. This may explain some of the differences between the two settings that the data collectors experienced in retrieving the data from the chart review.

Another limitation to chis study involves possible bias by the data collectors. The data collectors from both settings found the tool easier to use when reviewing patient scenarios that were familiar. This bias may have 
skewed the results of the completed tools, thereby diluting the value of the chart review as a means of data collection. Perhaps the nurse caring for the patient should complete the tool, or the patient should complete the tool, or the tool should be completed by a joint effort between the nurse and the patient. In a joint effort, the patient could chart the severity of the symptom and the nurse could chart the type of intervention implemented. This study suggests that it is best for the nurse to be familiar with the scenario in order for the ratings to be accurate. Since symptom severity is usually a subjective rating of the patient's perception, the nurse should collaborate with the patient to determine the accurate rating. Occasionally symptom severity is objective; for example, when a constipated patient has a bowel movement or a hyperglycemic diabetic has a blood sugar reading within a normal range. In these instances, the nurse is capable of rating symptom severity without much collaboration with the patient.

Another limitation to this study is the tool's lack of established statistical validity and reliability. To address the validity of the Corbin and Cherry Evaluation Tool for Chronic Illness Management testing criterion validity is ideal. For this study, a tool to measure nurse related symptom management was not located. However, now 
that symptom severity is identified as the measurable variable, tools to measure symptom severity can be investigated.

Another limitation in this study was that only one of the four data collectors wrote a brief description of the specific health provider action. Without this information a great deal of data was lost from the study. These data were missed due to the small print size of the instruction on the form to "briefly describe" the health provider action. This will be rectified before any future testing is done using the Symptom Severity Rating Form.

\section{significance of the study}

The significance of this study is that because the Symptom Management Rating Form was found to be a usable, workable tool, it is now available for future research. If a relationship can be demonstrated between the shift in severity of symptoms and nursing interventions, this tool will contribute greatly to nursing's ability to measure the effectiveness of nursing interventions. This contribution is vital to the nursing profession because it will enable nurses to support their worth in the health care delivery system through outcomes research. The question is where to focus future research to best measure the outcomes of nursing interventions.

Perhaps a setting where nurses are working 
autonomously and performing independent nursing interventions is most appropriate. There are many innovative models of health care delivery where nurses are working autonomously in the community. One such model is a nurse managed center. Nurse managed centers can costeffectively meet the health care needs of many underserved populations (Mackey, Adams, \& McNiel, 1994). Recently, research has begun to demonstrate the positive impact that nurse managed centers have on patient outcomes (Lasater, 1996). According to Corbin and Cherry (1997), nurse managed centers offer nurses the opportunity to deliver autonomous, client-centered care. Unfortunately, funding for nurse managed centers is limited, and until independent nursing functions are quantified and shown to reduce health care costs, the financial support for nurse managed centers is not strong. With the potential impact nurse managed centers have on patient outcomes, research using the Corbin and Cherry Evaluation Tool for Chronic Illness Management can help build support for the argument that payer sources should recognize nurse managed centers as cost effective health care providers and they should provide reimbursement or financial support for these services.

In addition, showing the value of independent nursing interventions through quantitative research will increase recognition that the nursing profession is important to 
patient outcomes. This research will keep nurses as a viable part of the health care delivery system.

\section{Summary}

Future research is needed to test the statistical validity and reliability of the Corbin and Cherry Evaluation Tool for Chronic Illness Management. Once the tool is shown to be statistically valid and reliable, further nursing research can be implemented using the tool to support the value and effectiveness of independent nursing interventions. As these independent nursing functions are substantiated, the nursing profession can grow and thrive in our ever-changing health care environment. 
REFERENCES 
References

Aiken, L. H., Smith, H. L., \& Lake, E. T. (1994). Lower Medicare mortality among a set of hospitals known for good nursing care. Medical Care, 32, 771-789.

Brooten, D., \& Naylor, M. D. (1995). Nurses' effect on changing patient outcomes. Image: Journal of Nursing Scholarship, 27, 95-99.

Cherkin, D. (1991). Methods and measurement in patient outcomes research: Universal issues. In National Institutes of Health, Patient outcomes research: Examining the effectiveness of nursing practice (DHHS publication No. 933411, pp. 154-158). Washington DC: U.S. Government Printing office.

Como, N. D. (Ed.) . (1990). Mosby's medical, nursing, and allied health dictionary (3rd ed.). St. Louis: Mosby.

Corbin, J. M. (1993, March). Chronic illness as a general phenomenon. Paper presented at the meeting of the Thomas Jefferson University, Nursing Scholar of the Year Award, Philadelphia, PA.

Corbin, J. M., \& Cherry, J. C. (1997). Caring for the aged in the community. In E. A. Swanson, \& T. Tripp-Reimer (Eds.), Chronic illness and the older adult (pp. 62-81). New York, New York: Springer.

Corbin, J. M., \& Strauss, A. (1991). A nursing model for chronic illness management based upon the trajectory framework. Scholarly Inquiry for Nursing Practice, 5, 155174 .

DeMoro, R. A. (1997, February). For this year's holiday travel: An unlicensed assistive pilot? California Nurse, 93 (2), 3 .

Dixon, W. J. (1993). Biomedical data processing statistical software manual. Berkeley: Univerity California Press.

Donabedian, A. (1976). Some basic issues in evaluating the quality of health care. In L. T. Rinke (Ed.), outcome measures in home care (Vol. 1, pp. 3-28). New York: National League of Nursing. 
Flaskerud, J. H. \& \& Halloran, E. J. (1980). Areas of agreement in nursing theory development. In L. H. Nicoll (Ed.), Perspectives on nursing theory (pp. 416-423). Philadelphia: Lippincott.

Frank-Stromberg, M. (1988). Instruments for clinical nursing research. East Norwalk, CT: Appleton \& Lange.

Glaser, B., \& Strauss, A. (1967). The discovery of grounded theory. Chicago: Aldine.

Griffiths, P. (1995). Progress in measuring nursing outcomes. Journal of Advanced Nursing, 21, 1092-1100.

Hartz, A., Krakauer, H., Kuhn, E., Young, M., Jacobsen, S., Greer, G., Muenz, L., Katzoff, M., Bailey, R. C. , \& Rimm, A. (1989). Hospital characteristics and mortality rate. New England Journal of Medicine, 321, 1720-1725.

Inouye, S. K., Wagner, D. R., Acampora, D., Horwitz, R. I., Cooney, L. M., \& Tinetti, M. E. (1993). A controlled trial of a nursing-centered intervention in hospitalized elderly medical patients: The Yale geriatric care program. Journal of the American Geriatrics Society, 41, 1353-1359.

Kennedy, L., Neidlinger, S., \& Scroggins, K. (1987). Effective comprehensive discharge planning for hospitalized elderly. The Gerontologist, 27, 577-580.

Lang, N. M., \& Marek, K. D. (1992). Outcomes that reflect clinical practice. In National Institutes of Health, patient outcomes research: Examining the effectiveness of nursing practice (DHHS publication No. 933411, pp. 27-38). Washington DC: U.S. Government Printing Office.

Lasater, M. (1996). The effect of a nurse-managed CHF clinic on patient readmission and length of stay. Home Healthcare Nurse, 14, 351-357.

Mackey, T. A., Adams, J., \& McNiel, N. O. (1994). Nursing centers: Service as a business. Journal of Nurse Economics, $12(5), 276-279$.

Mark, B. A. (1995). The black box of patient outcomes research. Image: Journal of Nursing Scholarship, 27,42 . 
National Institutes of Health. (1992). Patient outcomes research: Examining the effectiveness of nursing practice (NIH Publication No. 93-3411). Washington DC: U.S. Government Printing office.

Polit, D. F., \& Hungler, B. P. (1991). Nursing research: Principles and methods (4th ed.). Philadelphia: Lippincott.

Potter, P. A. \& Perry, A. G. (1989). Fundamentals of nursing concepts, process, and practice. St. Louis: Mosby.

Saylor, C. (1997). A classification scheme for health care outcomes evaluation. Unpublished manuscript, San Jose State University.

Snyder, M. (1985). Independent nursing interventions. New York: Wiley.

Snyder, M., Egan, E. C., \& Nojima, Y. (1996). Defining nursing interventions. Image: Journal of Nursing Scholarship, 28, 137-141.

Strauss, A. \& Corbin, J. M. (1988). Shaping a new health care system. San Francisco: Jossey-Bass.

Strauss, A. \& Corbin, J. M. (1990). Basics of qualitative method: Grounded theory procedures and techniques. Beverly Hills, CA: Sage.

Waltz, C. F., \& Strickland, O. L. (Eds.). (1988). Measurement of nursing outcomes (Vol. 1). New York: Springer.

Weisman, C. S. (1992). Nursing practice models: Research on patient outcomes. In National Institutes of Health, Patient outcomes research: Examining the effectiveness of nursing practice (DHHS Publication No. 933411, pp. 112-120). Washington DC: U.S. Government Printing office.

Woog, P. (Ed.). (1992). The chronic illness trajectory framework: The Corbin and strauss nursing model. New York: Springer. 
APPENDIX A

Symptom Management Rating Form

67 


\section{Corbin and Cherry Evaluation Tool for Chronic Ilness Management Symptom Management}

\section{Client Problem}

The health provider identifies and/or client complaius of having difficulty managing a symptom related to a chronic illness.

Rate degree of difficulty with symptom management BEFORE nursing interventions:

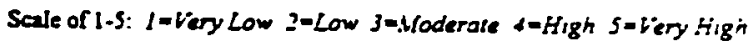

1. Energy deficit, fatigue.

2. Chronic pain, and episodic pain such as angina.

3. Changes in physiological functioning. Examples; constipation, urinary incontinence, difficulty swallowing, respiratory distress, hearing or vision impairment, dizziness, nausea, symptoms of hypo/hyper glycemia, muscle cramps, and sleep disturbance.

4. Changes in appetite.

5. Medication regimen and/or side effects.

$\begin{array}{lllll}1 & 2 & 3 & 4 & 5 \\ 1 & 2 & 3 & 4 & 5\end{array}$

\section{Health Provider Action}

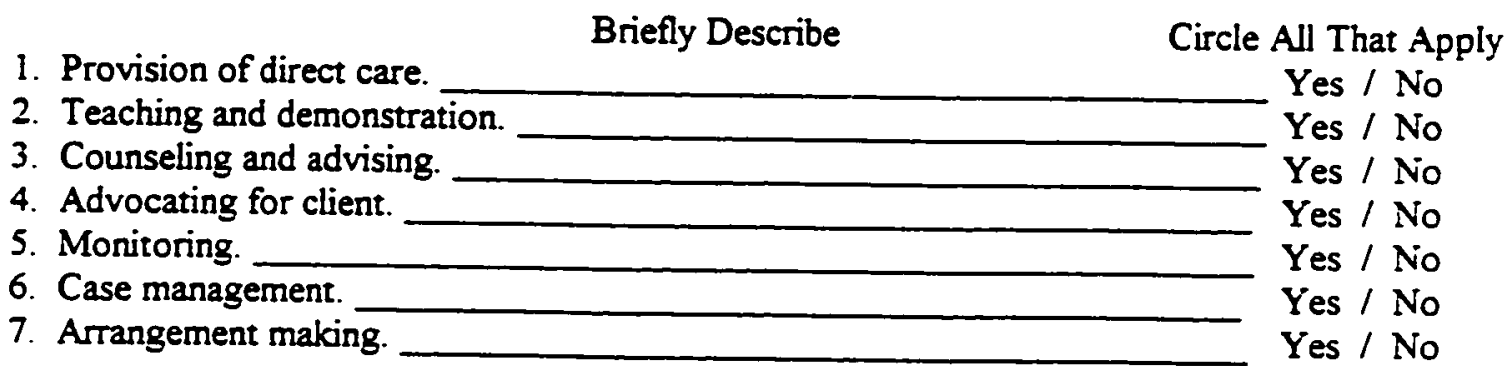

\section{Client Response}

Rate degree of difficulty with symptom management AFTER nursing interventions:

Sale of 1-5: 1-Hery Low 2-5ow 3--Woderate $f=H i g h s=$ Very High

1. Energy deficit, fatigue.

2. Chronic pain, and episodic pain such as angina.

$\begin{array}{lllll}1 & 2 & 3 & 4 & 5 \\ 1 & 2 & 3 & 4 & 5\end{array}$

3. Changes in physiological functioning. Examples; constipation, urinary incontinence, difficulty swallowing, respiratory distress, hearing or vision impaiment, dizziness, nausea, symptoms of hypo/hyper glycemia, muscle cramps, and sleep disturbance.

4. Changes in appetite.

5. Medication regimen and/or side effects.

$\begin{array}{lllll}1 & 2 & 3 & 4 & 5 \\ 1 & 2 & 3 & 4 & 5 \\ 1 & 2 & 3 & 4 & 5\end{array}$




\section{APPENDIX B}

\section{List of Trajectory Phases}




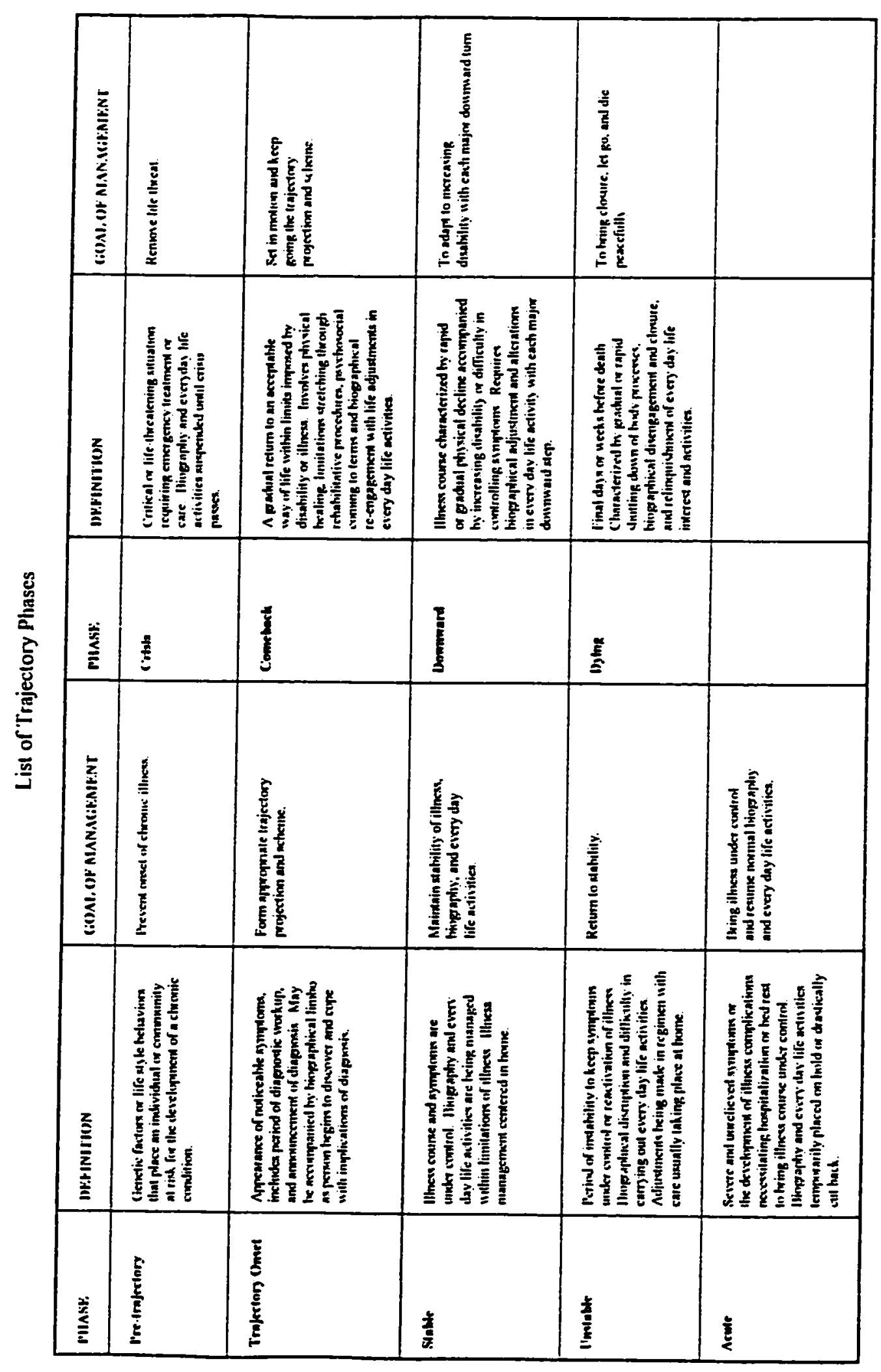


APPENDIX C

Visualization of Context 


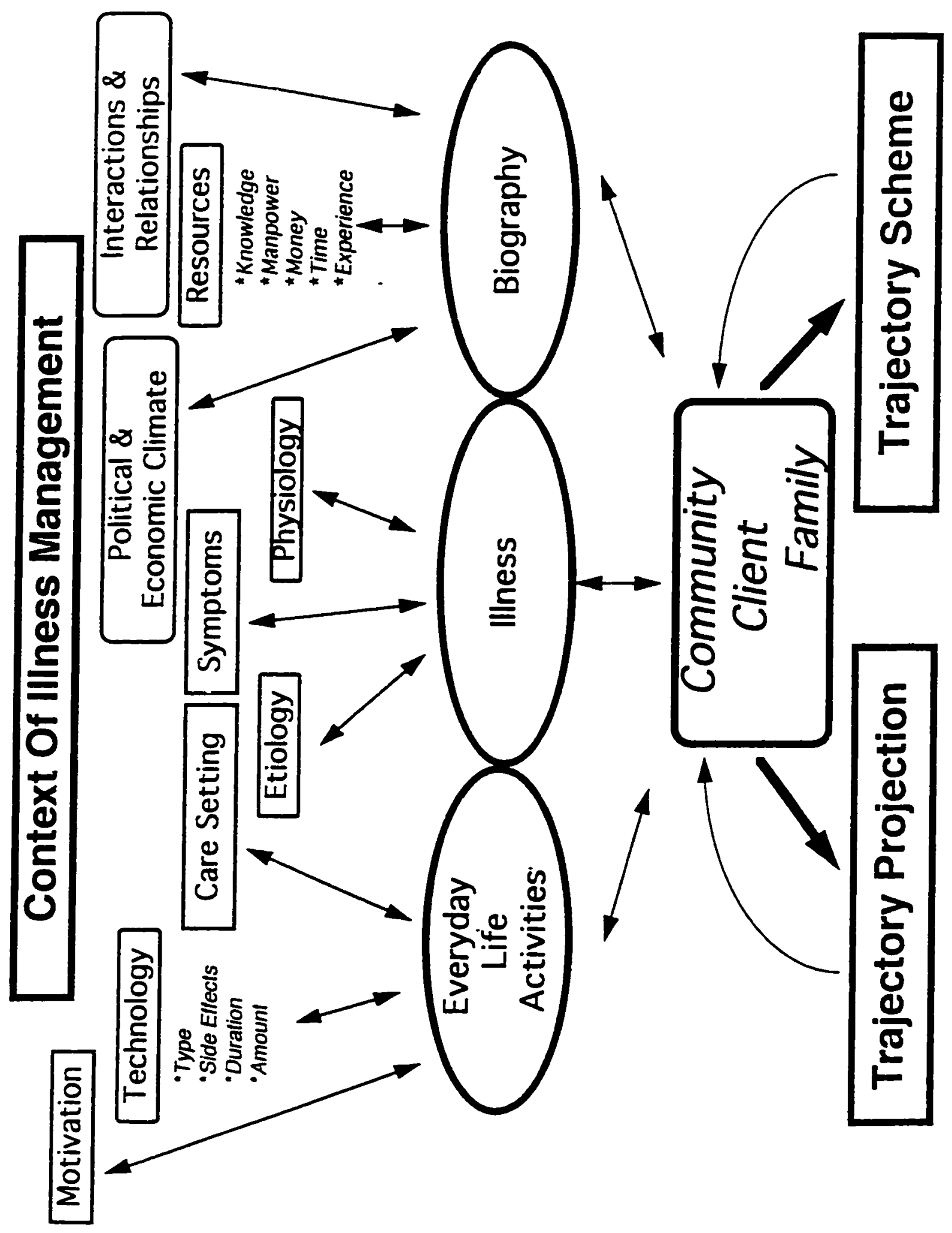


APPENDIX D

Memo to Case Managers Requesting Possible Subjects 


\section{TO: Case Managers and RNs}

\section{FROM: Julie Cherry}

Please help me identify patients that are appropriate for my thesis research. I need the names and PID\#s (if available) for any patient 65 years or older with a diagnosis of at least one chronic illness and a complaint or demonstration of difficulty managing a symptom related to a chronic illness. For example, a patient with CHF who is having difficulty managing SOB; or a patient with Diabetes who is having trouble controlling their blood sugars.

Please list as many patients as you can think of. It will be helpful to chose patients whose problems have been resolved (the symptom is now manageable).

\begin{tabular}{|l|l|}
\hline Patient Name & \\
\hline & \\
\hline & \\
\hline & \\
\hline & \\
\hline & \\
\hline & \\
\hline & \\
\hline
\end{tabular}




\section{APPENDIX E}

Approval From Columbia Homecare and Hospice 
COLUMBBIA

Homecare and Hospice

2025 G ATEMA: P:ACE. SLITE 260

SAIN IOSE, CALIFORN:A 95110

PHUNe (408) +52-1224

F ax $(408)+52-1260$

January 6, 1997

Julie Cherry, RN.

Columbia Homecare and Hospice

2025 Gateway Place, Suite $\$ 270$

San Jose, Califomia 95110

Dear Julie:

Following your presentation to the Columbia Homecare and Hospice Research Committee on November 25, 1996, the committee was pleased to approve your research project, "The Corbin and Cherry Evaluation Tool for Chronic Iliness Management." We look forward to hearing the result of your study. We wish you well as you complete the work for your Master's Degree at San Jose State University.

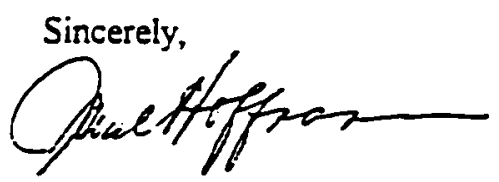

Jane M. Hoffmann, RV, MS

Chair, Research Review Committee

AMH:ceb 


\section{APPENDIX F}

Permission Letter from Chai Health Nurse Managed Center 


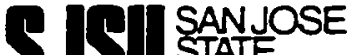

December 19, 1996

Julie Cheitlin Cherry RN, BSN

2312 Lacey Drive

Milpitas, CA 95035

Dear Ms. Cherry,

I read the summary of your research methodology. Your project is well thought out and has the potential to add knowledge to the nursing profession. You have my permission to use the health records at $\mathrm{CHAl}$ Health Center for your data collection. Please provide me a copy of your human subjects clearance.

Good luck with your project and best wishes for a happy holiday season.

Sincerely.

$$
\text { Ceypeloluer }
$$

Jayne Cohen, RN, NP, DNSC

Director, Nurse Managed Centers 
APPENDIX G

Approval Letter from San Jose State University Graduate Studies and Research 
TO:

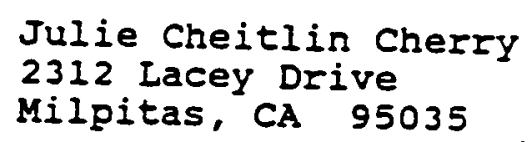

FROM :

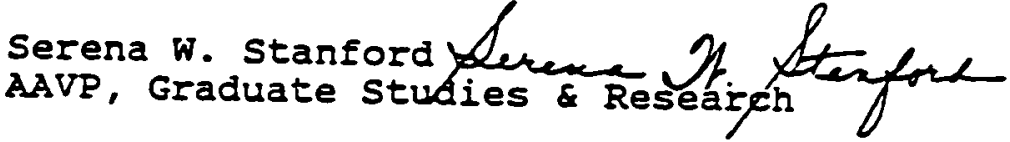

DATE :

February 21, 1997

The Human Subjects-Institutional Review Board has approved your request to use human subjects in the study entitled:

\section{"Validity and Reliability of the Corbin and Cherry Evaluation Tool for Chronic Illness Management"}

This approval is contingent upon the subjects participating in your research project being appropriately protected from risk. This includes the protection of the anonymity of the subjects' identity when they participate in your research project, and with regard to any and all data that may be collected from the subjects. The Board's approval includes continued monitoring of your research by the Board to assure that the subjects are being adequately and properly protected from such risks. If at any time a subject becomes injured or complains of injury, you must notify serena Stanford, Ph.D., immediately. Injury includes but is not limited to bodily harm, psychological trauma and release of potentially

Please also be advised that all subjects need to be fully informed and aware that their participation in your research project is voluntary, and that he or she may withdraw from the project at any time. Further, a subject's participation, refusal to participate, or withdrawal will not affect any services the subject is receiving or will receive at the institution in which the research is being
conducted.

If you have any questions, please contact me at (408) 924-2480. 
APPENDIX H

Demographic Data Sheet 
Demographic Data

Patient Identification Number

Facility: Columbia Chai Health Center

Patient Birth Date

Gender: Male

Female

List Chronic Illnesses:

Number of medications listed in medical record (include OTCs):

Specific symptom complaint: 
APPENDIX I

Code Book for Statistical Analysis 
Code Book

\begin{tabular}{|c|c|c|c|}
\hline Variable Name & Variable Description & Value Description & $\begin{array}{l}\text { Location in } \\
\text { File }\end{array}$ \\
\hline PN & Patient Identification Number & & \\
\hline$\overline{D C}$ & Data Collector & $\begin{array}{l}1=G E \\
2=T S T \\
3=K A \\
q=G L\end{array}$ & \\
\hline FAC & Facility & $\begin{array}{l}1=\text { Columbia } \\
2=\text { Chai Health }\end{array}$ & \\
\hline $\mathrm{BD}$ & Birhdate & $99=$ Missing & \\
\hline$\overline{G E N}$ & Gender & $\begin{array}{l}1=\text {.Wale } \\
2=\text { Female }\end{array}$ & \\
\hline $\mathrm{Cl}$ & Number of Chronic Inesses & 99=:Missing & \\
\hline MED & Number of Medications & 99=-lissing & \\
\hline SBNI & $\begin{array}{l}\text { Symptom Before Nursing } \\
\text { Intervention }\end{array}$ & $\begin{array}{l}\text { l= Energy Deficit } \\
2=\text { Pain } \\
j=\text { Physiological } \\
4=\text { Appetite } \\
j=\text { Medications }\end{array}$ & \\
\hline RBNI & $\begin{array}{l}\text { Rating of Symptom Management } \\
\text { Before Siursing Intervention }\end{array}$ & $\begin{array}{l}1=\text { Very Low } \\
2=\text { Low } \\
3=\text { :Loderate } \\
4=\text { High } \\
s=\text { Very High }\end{array}$ & \\
\hline HPAl & Provision of Direct Care & $\begin{array}{l}l=\text { Yes } \\
2=\text {.Vo }\end{array}$ & \\
\hline HPA2 & Teaching and Demonstration & $\begin{array}{l}1=\text { Yes } \\
2=N o\end{array}$ & \\
\hline FPA3 & Counseling and Advising & $\begin{array}{l}1=\text { Yes } \\
2=\text { No }\end{array}$ & \\
\hline HPAt & Advocating For Client & $\begin{array}{l}1=\text { Yes } \\
2=\text { Yo }\end{array}$ & \\
\hline HPAS & Monitoring & $\begin{array}{l}!=\text { Yes } \\
2=\text { No }\end{array}$ & \\
\hline HPA6 & Case Management & $\begin{array}{l}1=\text { Yes } \\
2=\text { : Yo }\end{array}$ & \\
\hline HPA7 & Arrangement Making & $\begin{array}{l}1=\text { Yes } \\
2=: \text { :io }\end{array}$ & \\
\hline SAVI & $\begin{array}{l}\text { Symptom After Nursing } \\
\text { Intervention }\end{array}$ & $\begin{array}{l}\text { 1= Energy Deficit } \\
2=\text { Pain } \\
3=\text { Physiological } \\
4=\text { Appetite } \\
\text { j= Medications }\end{array}$ & \\
\hline RANI & $\begin{array}{l}\text { Rating of Symptom Management } \\
\text { After Nursing Intervention }\end{array}$ & $\begin{array}{l}1=\text { Very Low } \\
9=\text { Low } \\
3=\text { Moderate } \\
+=\text { High } \\
\text { = = Very High }\end{array}$ & \\
\hline
\end{tabular}




\section{APPENDIX J}

Original Symptom Severity Rating Form 
The Corbin and Cherty Evaluation Toul for Chronic Illness Management

\section{Problems With Symptom Management Related to Trajectorv Onset or Instability of a Chronic Dlness}

Client Problem

Health provider identifies and/or client complains of having a degree of difficulty managing:

1. Energy deficit, fatigue.

2. Chronic pain, and episodic pain such as angina.

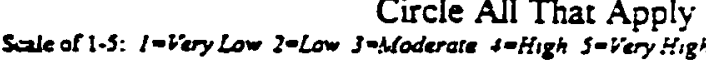

. Changes in physiological functioning Examples; constipatio incontinence, difficulty swallowing respiratory distress, hearing or vision impairment, dizziness, nausen, symptoms of bypo/hyper glycemia, and muscle cramps.

4. Changes in appetite.

5. Medication side effects.

Eealth Provider Action Briefly Describe Circle All That Apply How Appropriate

(Sale of 1-s; 1 -Not approprase $s=$ Was The Action

1. Provision of direct care. Yes / No 1 2 324

2. Teaching and demonsuration.

3. Counseling and advising.

4. Advocating for client.

5. Case management. Yes / No 112013045

6. Arrangement making Yes / No Yes / No Yes / No

7. Referral making. Yes / No Yes / No

\section{Client Response}

Total \# of Actions Taken

Client reports or demonstrates degree of management of:

Circle All That Apply

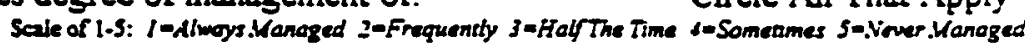

1. Energy deficit, fatigue.

$\begin{array}{lllll}1 & 2 & 3 & 4 & 5 \\ 1 & 2 & 3 & 4 & 5\end{array}$

2. Chronic pain, and episodic pain such as angina.

3. Changes in physiological functioning. Examples; constipation, urinary incontinence, difficulty swallowing, respiratory distress, hearing or vision impairment, dizziness, nausea, symptoms of hypo/hyper glycemia, and muscle cramps.

4. Changes in appetite.

5. Medication side effects.

$\begin{array}{lllll}1 & 2 & 3 & 4 & 5 \\ 1 & 2 & 3 & 4 & 5 \\ 1 & 2 & 3 & 4 & 5\end{array}$

\section{General Outcome}

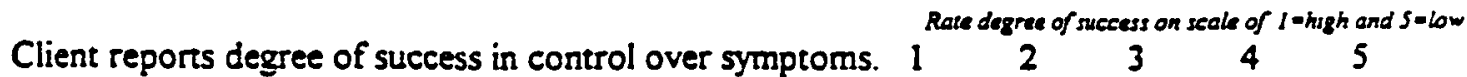


APPENDIX K

List of Questions for Content Experts to Address 
Please consider the following items when reviewing the Corbin and Cherry Evaluation Tool for Chronic Illness Management.

1. Is the terminology used in the tool understandable? What recommendations do you have regarding terms used in the tool?

2. Is it clear how one would fill out this tool. Are the scales clearly marked and easy to decipher?

3. Do the nursing action categories conceptually encompass all conceivable nursing interventions?

4. In your opinion is this tool measuring what it is intended to measure?

5. It is intended that this tool will show a shift in degree of difficulty managing symptoms from high to low by rating the degree of difficulty with symptom management both before and then again after nursing interventions. In your opinion, can this tool document such a shift and is it therefore, measuring the effectiveness of nursing interventions?

6. What other comments or recommendations do you have for improving this measurement tool? 